\title{
Performance of selected polyurethane joint sealants in concrete structures
}

\author{
Barbora Nečasová ${ }^{1, *}$, Pavel Liška ${ }^{1}$, and Jiř Šlanhof $^{1}$ \\ ${ }^{1}$ Brno University of Technology, Faculty of Civil Engineering, Veveři 331/95, Brno 602 00, Czech \\ Republic
}

\begin{abstract}
Often underestimated and neglected, joint sealants in concrete structures play an important role in protecting the structure against its premature deterioration. The focus of the presented paper lays upon the issue of sealing of joints in concrete structures. Concrete is one of the most difficult materials to seal since there are always small particles of dust and the material itself. In this paper, the joint will be viewed as traditional expansion joint. Two representatives of flexible one component polyurethane sealants were selected. The main reason for this selection was that conventional repair materials are usually very rigid and easily incline towards the formation of cracks and gaps. The aim of this paper is not only to verify the suitability of selected materials but also to demonstrate that polyurethane sealants might be a better and long-lasting solution for filling of joints and patching of cracks within concrete structures.
\end{abstract}

\section{Introduction}

From time immemorial, building structures have been designed such that they are able to withstand the contrary effects of the environment for a certain time. The terms "for a certain time" and "the surrounding environment" are used for a purpose here, and that is because the phenomenon of ageing buildings is currently an increasingly discussed problem that is faced by every larger city [1-5]. The materials used in the buildings (such as sealants) age just as the buildings themselves do. Their ageing can affect their mechanical properties and functionality. The surrounding environment affects the materials in the same way, therefore, they are no longer able to fulfil the task for which they were designed, which may also result in the degradation of the building itself.

Currently, there are countless sealants, filling adhesives and materials on the market, so it is not surprising that designers often scratch their heads over the question of what sealant to use in the design, whether the selected sealant is suitable for use in the proposed combination of materials etc. Unfortunately, this lack of information and knowledge can greatly accelerate the ageing of the selected sealant and irreversibly damage the whole structure. While some products have a service life as low as three or four years, see Fig. 1 (C, D), today we already know that some silicones can last up to 25 years in the case of a correct installation [6].

\footnotetext{
*Corresponding author: necasova.b@fce.vutbr.cz
} 
In this paper, the authors focused on the sealants of concrete structures, as this is the most used building material at present. Concrete is a composite material, i.e. an "agglomerate" of more raw materials, and it is generally known that after plastics, it is the material that has the most complicated material properties for sealing [7,8]. It is very common that the joints between individual concrete elements must be protected from environmental influences, the permeation of moisture and so forth, see examples in Fig. 1 (part A and B).
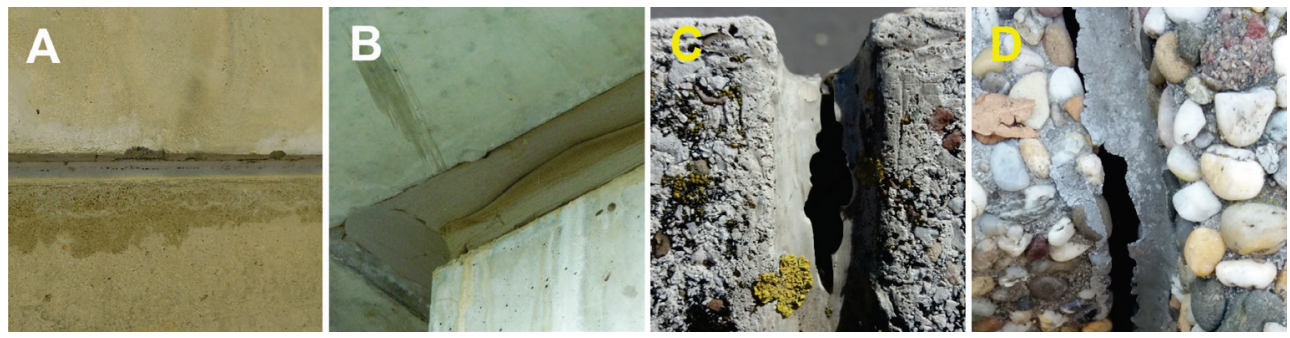

Fig. 1. Joint between concrete elements (A, B) and common types of joint sealant failure (C, D).

An inappropriately selected filling material may not adhere sufficiently to the concrete structure and thus not fulfil the function for which it was designed, see Fig. 1 (part C and D). The aim of the authors of this article was to test two polyurethane sealants from the same manufacturer which are, on the one hand, designed for sealing concrete structures, but are also commonly available in the market.

\section{Methodology}

The presented work comprised two parts. Firstly, the maximum elongation of the tested sealants at break was evaluated by extension test. The elongation at break as well as maximum force applied were recorded and calculated. Secondly, the failure modes of all samples that appeared during testing were observed to express the compatibility of tested materials. However, the main aim of this case study was to compare results obtained from tests performed on samples that were manufactured in perfectly clean environment of laboratory, and on samples that were prepared, cured and stored in an external environment.

\subsection{Materials}

The selection of materials for presented case study was based on an already completed project. The results of this project $[7,8]$ showed that only polyurethane sealants are able to, a certain level, fulfil the high requirements for sealing of concrete structures. Hence, two representatives of high strength one-component polyurethane sealants from the same manufacturer were selected.

Table 1. Mechanical properties of selected sealants.

\begin{tabular}{|l|c|c|}
\hline Property/Sealant & Type I & Type II \\
\hline Tear Strength at Break $\left[\mathrm{N} / \mathrm{mm}^{2}\right]$ & 8 & 8 \\
\hline Shore A & 37 & 37 \\
\hline Secant Modulus $/ 100 \%$ elongation $\left[\mathrm{N} / \mathrm{mm}^{2}\right]$ & 0,6 & 0,6 \\
\hline Elongation at Break $[\%]$ & $>600$ & $>700$ \\
\hline Elastic Recovery $[\%]$ & $>90$ & $>80$ \\
\hline Service Temperature $\left[{ }^{\circ} \mathrm{C}\right]$ & \multicolumn{2}{|c|}{-40 up to +70} \\
\hline
\end{tabular}


Both selected representatives are adhesive even without the use of penetration coatings and/or activation agents. However, according to the information that are described in technical data sheets, it is advisable to use an overcoat for optimum adhesion in critical and high-performance applications. Moreover, in the case of concrete structures, the application of the improving liquid is actually recommended. Comparison of mechanical properties can be seen in the Table 1 .

The information presented in Table 1. show that both selected sealants have very similar material properties, however, the first selected sealant, hereinafter Type I, can be classified as sealant for non-structural use in joints in buildings and pedestrian walkways [9]. It should provide perfect performance when joining concrete structures or elements. Therefore, this sealant has been designed predominantly for the purpose which was tested in the presented case study. On the contrary, Type II sealant can be classified as an universal filling material. According to the technical data sheet [9] this product should provide an excellent adhesion on all cement-based materials, brick, ceramics, glass, metals, wood etc. Therefore, worse adhesion to concrete elements can be expected.

The concrete elements were prepared from dry mix concrete B20 for strength class $\mathrm{C} 16 / 20$. The geometry of all elements was $40 \times 40 \mathrm{~mm}$ in cross section and $160 \mathrm{~mm}$ long.

\subsection{Methods}

Although joint sealing may seem like a simple task, the method and discipline of this work is very demanding. When applying selected sealants, it is necessary to adhere to technological discipline and proceed according to the manufacturer's instructions. The discipline of preparation and application relates mainly to the preparation of the substrate, i.e. the sealed structure. The substrate must be clean, dry, homogeneous, and free of oils, grease, dust and of free or non-cohesive particles. Therefore, the preparation of the samples and the subsequent application of the sealant was carried out according to the principles and procedures specified by the producer of the individual system. Generally, the edges of all samples were cleaned of dust using the cleaning product from the system before the actual sealing was performed. To achieve maximum adhesion, primer was used in all cases.

The same preparation and application procedure was used for the test samples prepared in the laboratory as well as for those prepared in the exterior. Three test samples were produced for each exposure period for the testing of normal stress.

The used method for determination of joint sealants performance was a 'real joint' method [10]. The aim of the method is to test samples that were prepared the same way as if the joint was installed in real structure [10]. Hence, the sealant joint of $10 \mathrm{~mm}$ thickness and $10 \mathrm{~mm}$ width was prepared. The preparation and geometry of test samples can be seen in Fig. 2.
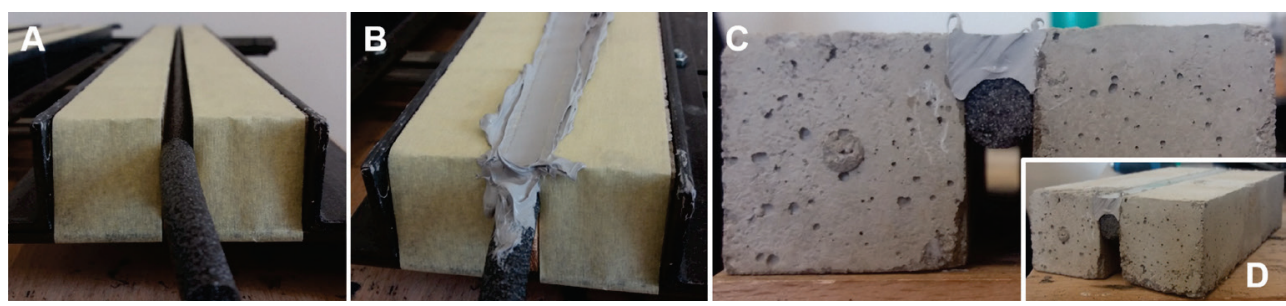

Fig. 2. Specimen manufacturing (A, B) and geometry (C, D).

After preparation of test samples always follows the curing period. However, in this case study, the length of the curing period was the key element, since some samples were manufactured, cured and stored in laboratory, where they were left in a perfectly dry and 
clean environment (at $23 \pm 2{ }^{\circ} \mathrm{C} / 50 \pm 10 \%$ humidity), for a specific period, so that they aged sufficiently. On the contrary, some samples were manufactured, cured and stored in the environment with direct exposure to weather changes. Test samples were tested after 1, 3, 6 and 12 months of curing. Results of samples tested after 1 month, i. e. 28 days, were also used as a reference standard for the evaluation of test data.

Before the testing itself, the measuring of the width of the joint was performed after c. 48 hours, see chapter Results. Subsequently, the test samples were placed into test moulds, see Fig. 4 (A) and extended at a speed of approximately $(5.5 \pm 0.7) \mathrm{mm} /$ minute. The testing was performed in the following steps:

- Step 1.: Extension of the joint to $100 \%$ of the original width.

- Step 2.: Extension of the sample for the period of 24 hours.

- Step 3.: After 24 hours, extension of the sample until the break.

- Step 4.: Recording of failure modes.

\section{Results}

The width of the joint was measured before the commencement of the testing so that it was possible to determine whether there occurred any deformation of the sealants during the exposure period. The width of the real joint was measured in three points with the use of Vernier callipers. The measured values were averaged and a representative width of the sealed joint was obtained. Based on this average value, a so-called normalized value of the joint width was determined according to equation (1). The normalized value less than 1 indicated that the joint sealant was in a compressive state and a normalized value close to 0 indicates more compression of the joint sealant with respect to the original width. Values higher than 1 prove the elongation of the real joint.

$$
N V=\left(l_{1} / l_{0}\right)
$$

where NV is normalized value [-], $1_{0}$ is the original joint width measured after 48 hours after manufacturing in $\mathrm{mm}$ and $l_{1}$ is the joint width after specific exposure period and before testing in $\mathrm{mm}$.

Another objective was to establish the size of the joint deformation which in this case is represented by its relative elongation that can be expressed in \% as joint tensibility. The tensibility was determined based on an equation (2).

$$
\delta=\left(\Delta l / l_{l}\right) \times 100 \%
$$

where $\delta$ is tensibility in $\%, \Delta \mathrm{l}$ is a change of joint width in $\mathrm{mm}$ and $l_{1}$ is the joint width measured before testing in $\mathrm{mm}$.

The measured values were subsequently used to determine the approximate stress-strain curve, to find the relation between joint deformation and the level of extension resistance. The formula for calculation of an average force needed for the joint deformation was derived from a standard formulation of Hook's law, see equation (3).

$$
\Delta l=\left(F \times l_{1}\right) /(E \times A)=\left(\sigma \times l_{1}\right) / E
$$

where $\Delta \mathrm{l}$ is a change of joint width in $\mathrm{mm}, \mathrm{l}_{1}$ is the joint width measured before testing in $\mathrm{mm}, \mathrm{F}$ is the maximum force in $\mathrm{N}, \mathrm{E}$ is modulus of elasticity in $\mathrm{N} / \mathrm{mm}^{2}, \mathrm{~A}$ is bonded area in $\mathrm{mm}^{2}$ and $\sigma$ is strain in $\mathrm{N} / \mathrm{mm}^{2}$. 
Table 2. Comparison of test results.

\begin{tabular}{|l|l|c|c|c|c|}
\hline Property/Sealant & $\begin{array}{c}\text { Exposure } \\
\text { period }\end{array}$ & \multicolumn{2}{c|}{ Type I } & \multicolumn{2}{c|}{ Type II } \\
\hline Storing Environment $[-]$ & & LAB & EXT & LAB & EXT \\
\hline Average Maximum Elongation at & 1 month & 50,67 & $\mathbf{6 5 , 6 4}$ & 54,27 & $\mathbf{6 1 , 8 3}$ \\
Break [mm] & 3 months & $\mathbf{6 2 , 4 3}$ & 57,27 & $\mathbf{5 7 , 9 7}$ & 47,45 \\
& 6 months & $\mathbf{5 8 , 9 9}$ & 57,97 & $\mathbf{4 8 , 9 0}$ & 44,25 \\
& 12 months & $\mathbf{6 5 , 5 5}$ & 58,67 & 41,97 & $\mathbf{5 4 , 2 1}$ \\
\hline Average Tensibility $\delta[\%]$ & 1 month & 352,6 & $\mathbf{4 6 4 , 1}$ & 391,3 & $\mathbf{4 1 9 , 7}$ \\
& 3 months & $\mathbf{4 3 2 , 5}$ & 423,2 & $\mathbf{4 4 8 , 7}$ & 358,3 \\
& 6 months & $\mathbf{4 7 9 , 3}$ & 469,7 & $\mathbf{3 6 7 , 7}$ & 331,7 \\
& 12 months & $\mathbf{5 4 4 , 4}$ & 476,6 & 314,7 & $\mathbf{4 2 7 , 3}$ \\
\hline Average Maximum Force $[\mathrm{N}]$ & 1 month & 3384,8 & $\mathbf{4 4 5 5 , 4}$ & 3757,0 & $\mathbf{4 0 2 8 , 8}$ \\
& 3 months & $\mathbf{4 1 5 2 , 1}$ & 4062,7 & $\mathbf{4 3 0 7 , 2}$ & 3439,5 \\
& 6 months & $\mathbf{4 6 0 0 , 9}$ & 4509,6 & $\mathbf{3 5 3 0 , 3}$ & 3184,7 \\
& 12 months & $\mathbf{5 2 2 6 , 2}$ & 4575,7 & 3021,2 & $\mathbf{4 1 0 1 , 7}$ \\
\hline Average Stress Strain $\left[\mathrm{N} / \mathrm{mm}^{2}\right]$ & 1 month & 2,12 & $\mathbf{2 , 7 8}$ & 2,35 & $\mathbf{2 , 5 2}$ \\
& 3 months & $\mathbf{2 , 6 0}$ & 2,54 & $\mathbf{2 , 6 9}$ & 2,15 \\
& 6 months & $\mathbf{2 , 8 8}$ & 2,82 & $\mathbf{2 , 2 1}$ & 1,99 \\
& 12 months & $\mathbf{3 , 2 7}$ & 2,86 & 1,89 & $\mathbf{2 , 5 6}$ \\
\hline
\end{tabular}

\section{Analysis}

As can be seen from the presented results, the aim of the authors was not only to record the maximum force needed to break the test specimens, but also to assess the way in which all the cracked joints break, since in the case of selected sealants, the maximum forces are reached only rarely when the sample breaks.

From the results of failure modes presented in Fig. 4., can be seen that for all test specimens left in a clean laboratory environment, only one manner of failure mode was recorded, namely the cohesive failure. As can be seen from Fig. $3(\mathrm{C})$, the sealed joint almost always cracked right at its centre at an elongation of up to $500 \%$. As was expected, the test specimens that were left in the laboratory environment were completely protected against weathering and the effects of weather changes and their ageing was thus not accelerated. Nevertheless, shrinkage was monitored for all test samples. This was confirmed by the calculation of the normalized value. Eventhough, the differences of compression between sealants tested in laboratory and in exterior have not been considerably high, the normalized value showed that samples stored in exterior compressed a little bit more, approximately about $10 \%$, than those stored in interior.
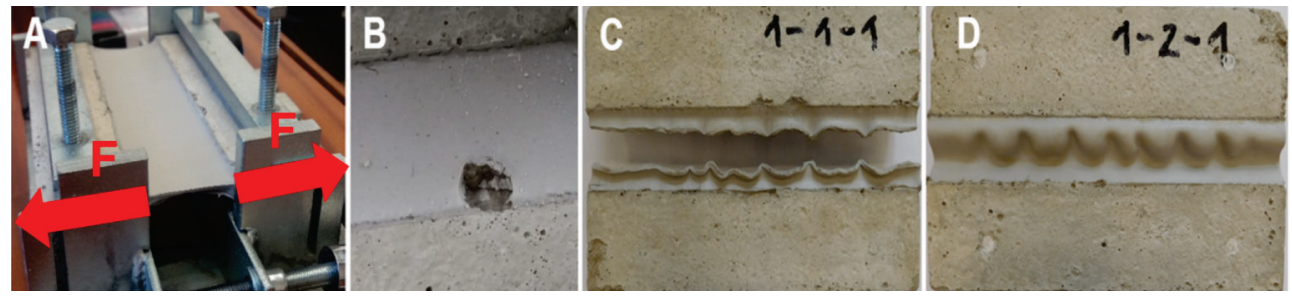

Fig. 3. Test samples inserted in moulds (A) and examples of failures (B-D).

The results obtained from the laboratory measurements were compared with the results that were measured for the samples produced and left in an outdoor environment, see the results presented in Table 2. and Fig. 4. Here, however, the same failure modes as well as 
similar elongations were recorded, only in two cases no failures were recorded and permanent deformation of c. $40 \%$ had been measured, see Fig. 3. (D) with an example of permanent deformation of joint sealant. In addition to the dominant number of cohesive failures only two samples embodied a combination of adhesive and cohesive failure, see Fig. 3. (B). Eventhough, the effects of ageing were monitored for all the samples, which should have an effect on the reduction of the elasticity of the applied sealant, no effect was observed in any case, and thus also any effect of ageing and of external environment have not been monitored. Moreover, the external environment has not had any influence on the resulting maximum elongation which can be seen in Table 2. where the maximum values had been highlighted.

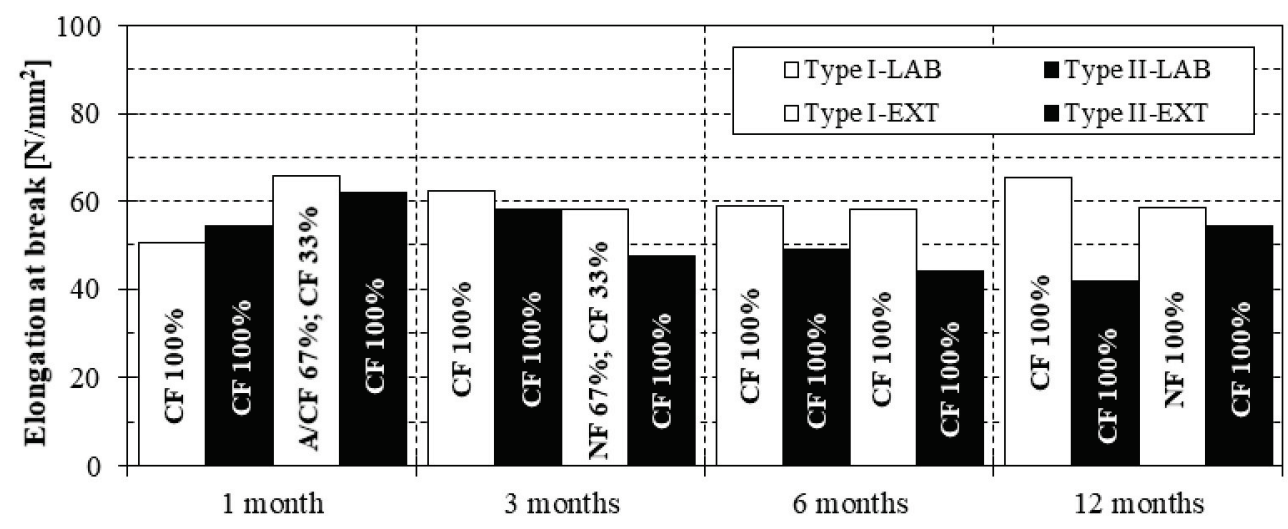

Fig. 4. Comparison of ultimate elongations at break of test samples.

\section{Conclusion}

The measured results demonstrate the suitability of the selected sealants for use in sealing concrete structures. Contrary to the initial expectations, no significant differences were found between the sealants used. While the only good properties for sealing concrete structures were confirmed for the Type I sealant, for the Type II sealant, the results of the case study demonstrated that even a universal sealant can be used to seal more complicated materials and structures without any problems.

However, the truth is such that this sealant is only an exception and, as has been mentioned already in the introduction to this paper, every combination of the proposed materials, a sealant and concrete structure in this case, should be tested at least in the way presented here before its application.

\section{References}

1. D.C.W. Ho, Property Management 11 (3), 6 (1993)

2. S.H. Ng, P.K. Kam, R.W.M. Pong, J. Environ. Psychol. 25 (3), 14 (2005)

3. D.J. Stobbelaar, B. Pedroli, Landscape Research 36 (3), 19 (2011)

4. D.C.W. Ho, Y. Yau, Ch. Law, E. Luisman, Urbani Izziv 23 (1), 15 (2012)

5. H.O. Nigro, S.E. González Císaro, Cities 56, 6 (2016)

6. J.C. Beech, A.T. Wolf, Durability of Building Sealants (Routledge, 2013)

7. J. Šlanhof, M. Šimáčková, P. Liška, B. Nečasová, Proceedings of Construction Technology and Management (CTM 2014), 9 (2014)

8. J. Šlanhof, B. Nečasová, P. Liška, M. Šimáčková, AMM 824, 8 (2016)

9. Sika CZ, s.r.o., Product data sheet. Available on http://sika.cz (2017)

10. B. Nečasová, P. Liška, J. Šlanhof, Proc. Eng. 109 (2017) 